\title{
Studies with Tritiated Digoxin in Renal Failure and Diabetes Mellitus
}

\author{
Hideo Ueda, M.D., Tatsuya Motoki, M.D., Kikuo Machida, M.D., \\ Shigekoto Kainara, M.D., Masahiro IIo, M.D., Hisakazu YAsudA, M.D., \\ and Satoru Murao, M.D.
}

The present study was made to obtain the information about the serum levels and excretion of digoxin after intravenous administration of the tritium labeled compound in the patients with renal failure and diabetes mellitus. Three patients with renal failure, 5 patients with diabetes mellitus and 3 control patients were studied. In renal failure the clearance of digoxin was markedly impaired. The blood level of this group remained high for a long time, urinary excretion was much decreased and fecal excretion was increased. This observation shows that the kidney is the major organ for excretion of digoxin in normal subjects. Blood dialysis and peritoneal lavage were performed and revealed to have little effect on removal of digoxin from blood. In diabetes mellitus the diabetic state or the usuage of anti-diabetic drugs had no influence on clearance of digoxin and the degree of impaired renal function was recognized as a factor of the clearance of digoxin.

$\mathrm{I}^{\mathrm{m}}$ $T$ is highly desirable to elucidate the metabolism of digitalis in human body in view of variations of effective or toxic doses in individual clinical cases. The recent availability of radioactive digitalis has made it possible to investigate the metabolism of the compounds more in details. Since 1951 much information has been accumulated in regard to the metabolic behavior of digitoxin in the human body using the $\mathrm{C}^{14}$ labeled glycoside. ${ }^{1)-3)}$ Until 1961 similar studies with digoxin had not been possible because of the expense and difficulty of obtaining $\mathrm{C}^{14}$ labeling, when Doherty found the utility of tritiated digoxin in such studies. ${ }^{4}$ ) Thereafter, a number of reports on the digoxin metabolism have been made. ${ }^{51-10}$

The purpose of the present study was to obtain the informations about the serum levels and excretion of digoxin after intravenous administration of the tritium labeled compound in the patients with renal insufficiency and diabetes mellitus. Tokyo.

From the Second Department of Internal Medicine, Faculty of Medicine, University of Tokyo,

Received for publication January 20, 1967.

This paper was read before the 13th Annual Meeting of the Society of the Nuclear Medicine (June 1966, Philadelphia). 


\section{Materials and Methods}

Tritium labeled digoxin was prepared by the Wilzbach hydrogen-exchange method.*11) Radioactive impurities and by-products were removed by column partition chromatography.** The purified products were supplied in ampules containing $1.0 \mathrm{mg}$. of tritiated digoxin in $1 \mathrm{ml}$. of 95 per cent ethanol. Assays revealed specific radioactivities of $112 \mu \mathrm{Ci}$. per mg. of tritiated digoxin.

Subjects studied are as follows: Three patients hospitalized with renal failure, diagnosed as such by the presence of chronic glomerulonephritis, elevated blood urea nitrogen (above $100 \mathrm{mg}$. per $100 \mathrm{ml}$.) and impaired renal function tests. Five patients with diabetes mellitus, determined by elevated fasting blood sugar (above $140 \mathrm{mg}$. per $100 \mathrm{ml}$.) and glucose tolerance tests, not in uremic state except one case who was proved to be diabetic glomerulosclerosis of nodular type by renal biopsy and

Table I. Clinical Informations of the Patients with Renal Failure

\begin{tabular}{|c|c|c|c|c|c|c|c|c|}
\hline \multirow{2}{*}{$\begin{array}{l}\text { Case } \\
\text { No. }\end{array}$} & \multirow{2}{*}{ Name } & \multirow{2}{*}{ Sex } & \multirow{2}{*}{ Age } & \multirow{2}{*}{ Diagnosis } & \multirow{2}{*}{$\begin{array}{c}\text { BUN } \\
\text { (mg./100 } \\
\text { ml.) }\end{array}$} & \multicolumn{2}{|c|}{ PSP $(\%)$} & \multirow{2}{*}{$\begin{array}{l}\text { Renal Clearance } \\
\text { (ml./min.) }\end{array}$} \\
\hline & & & & & & $15 \mathrm{~min}$. & $2 \mathrm{hrs}$. & \\
\hline 1 & M. S. & $\mathrm{m}$ & 24 & chronic glomerulonephritis & 123 & - & - & $\begin{array}{l}\text { GFR 2.4, RBF } \\
2.5, \text { RPF } 2.0\end{array}$ \\
\hline 2 & M. H. & $\mathrm{m}$ & 32 & chronic glomerulonephritis & 103 & 0 & 0 & - \\
\hline 3 & N. A. & f & 25 & chronic glomerulonephritis & 151 & below 5 & - & - \\
\hline
\end{tabular}

Table II. Clinical Informations of the Patients with Diabetes Mellitus

\begin{tabular}{|c|c|c|c|c|c|c|c|c|}
\hline \multirow{2}{*}{$\begin{array}{l}\text { Case } \\
\text { No. }\end{array}$} & \multirow{2}{*}{ Name } & \multirow{2}{*}{ Sex } & \multirow{2}{*}{ Age } & \multirow{2}{*}{ Diagnosis } & \multicolumn{3}{|c|}{ Glucose Tolerance Test ${ }^{\dagger}$} & \multirow{2}{*}{$\begin{array}{c}\text { Sugar in } \\
\text { Urine (Gm./day) }\end{array}$} \\
\hline & & & & & before & 2 hrs. & $3 \mathrm{hrs.}$ & \\
\hline 4 & Si. S. & f & 73 & $\begin{array}{l}\text { Kimmelstiel-Wilson } \\
\text { syndrome }\end{array}$ & 160 & - & - & $5-20$ \\
\hline 5 & Su. S. & $\mathrm{f}$ & 66 & $\begin{array}{r}\text { diabetes mellitus } \\
\text { + hypertension }\end{array}$ & 152 & 330 & 345 & $6-50$ \\
\hline 6 & T. K. & $f$ & 61 & $\begin{array}{l}\text { diabetes mellitus + arterio- } \\
\text { sclerotic heart disease }\end{array}$ & 246 & 348 & 316 & $5-15$ \\
\hline 7 & S. M. & $f$ & 33 & diabetes mellitus & 282 & 314 & 350 & $3-6$ \\
\hline 8 & S. N. & $f$ & 51 & diabetes mellitus & 108 & 200 & 176 & $1-3$ \\
\hline
\end{tabular}

$+\mathrm{mg} \cdot 100 \mathrm{ml}$

* New England Nuclear Corporation, Boston, Massachusetts

** Burroughs Wellcome \& Co., Inc., Tuckahoe, N. Y. 
whose blood urea nitogen was $64 \mathrm{mg}$. per $100 \mathrm{ml}$. Three cotrol patients who had neither metabolic nor renal diseases. The clinical informations of the patients were summarized in Table I and II.

The dose of tritiated digoxin injected was $0.23 \mathrm{mg}$, diluted in $10 \mathrm{ml}$. of normal saline solution. The solution was gradually administered intravenously in $1 \mathrm{~min}$., zero time being considered at the end of injection. Specimens of venous blood were obtained from the opposite antecubital vein at 10 and $30 \mathrm{~min}$. and at 1, 2, 4, 6, 12 and 24 hours after injection. The blood was heparinized and then refrigerated. Daily urine was collected for 8 to 14 days. Stools were collected daily for 7 to 14 days.

Specimens were prepared for analysis by the following methods. One ml. of blood or urine was mixed with $15 \mathrm{ml}$. of PE-61 1 scintillator, ${ }^{121}$ consisting of $750 \mathrm{~m}$. of dioxane, $135 \mathrm{ml}$. of anisole, $135 \mathrm{ml}$. of dimethoxyethane, $12 \mathrm{Gm}$. of PPO and $400 \mathrm{mg}$. of POPOP. After $30 \mathrm{~min}$. mixture was filtered into counting vial and washed with $1 \mathrm{ml}$. of the scintillator for two times. Then, the radioactivities in the samples were extracted almost completely into the scintillator for counting. Stools were combusted with Schöniger combustion method.13) In a round bottomed flask, $\mathrm{H}^{3}$ label was changed into tritiated water which was dissolved by a scintillator, consisting of $800 \mathrm{ml}$. of toluene, $200 \mathrm{ml}$. of ethanol, $4 \mathrm{Gm}$. of PPO and $100 \mathrm{mg}$. of POPOP.

Counting was performed with a Packared Tri-Carb liquid scintillation spectrometer. Actual counts were corrected for quenching by automatic external standardization method. More than 96 per cent of the total radioactivity in the specimens were recovered with these steps.

The chromatographical analysis was performed on urine according to Gonzalez $^{10)}$ and Gisvold ${ }^{14)}$ to measure the percentage of metabolites of digoxin in the whole radioactivities.

Turnover study was carried out on 2 patients of the renal failure group prior to and during the following procedures, that is, one patient (M.S.) subjected to blood dialysis and another (N.A) subjected to peritoneal lavage. After the patients were given $0.23 \mathrm{mg}$. of tritium labeled digoxin three times on the serial 3 days the blood dialysis and peritoneal lavage were performed. Digoxin was administered to the patients 2 hours before dialysis to allow the better equilibration of serum concentration. Blood dialysis was continued for 6 hours until clinical benefit seemed to be obtained. On the other hand, in the patient (N.A.) $1.0 \mathrm{~L}$. of lavage fluid was allowed to remain in the periotoneal cavity for one and a half hours and this procedure was repeated six times successively in 9 and a half hours. The dialyzed fluid and peritoneal fluid were then analyzed for radioactivity by the same method as blood or urine. Blood specimens were obtained every 3 days in the same manner as described above.

\section{Results}

The time course of blood level of radioactivity was varying in each group (Fig. 1). When control group was compared with both renal failure and diabetes mellitus, significant decrease in clearance was observed in the latter groups with higher blood level of radioactivity in 24 hours after injection. Among 


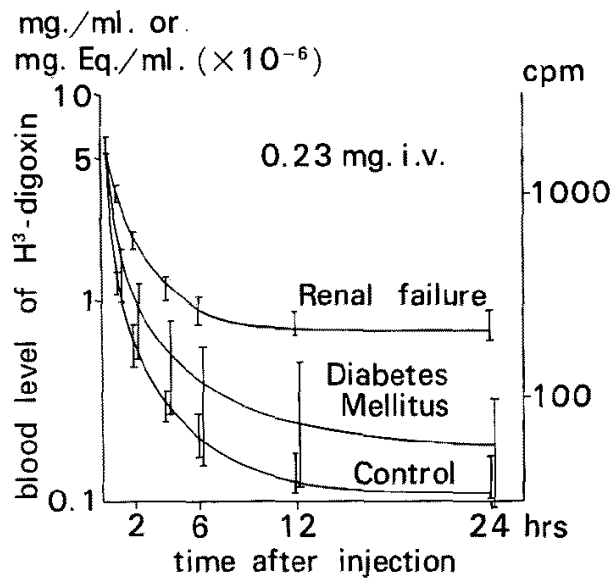

Fig. 1. The time course of blood level of radioactivity after intavenous administration.
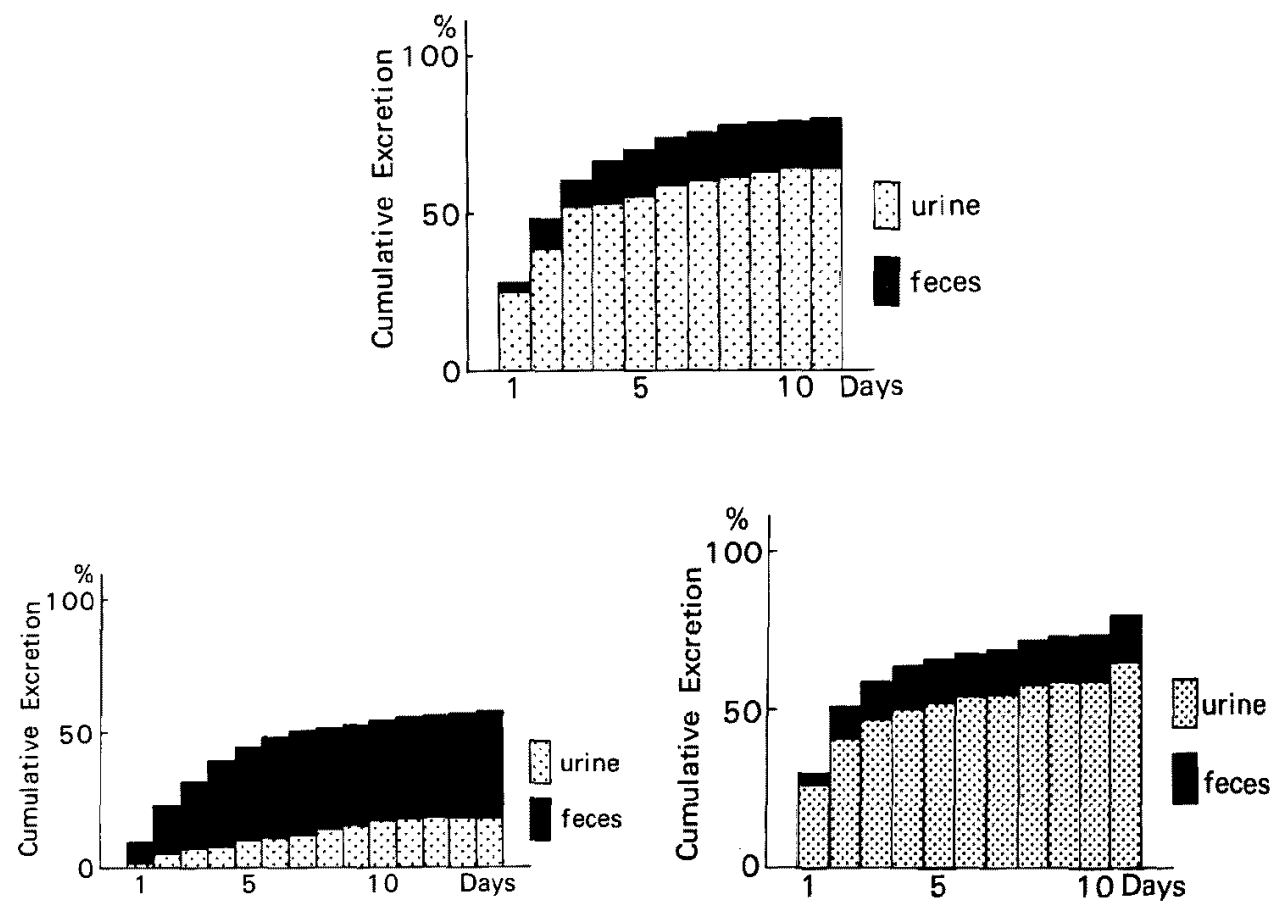

Fig. 2. The fecal and urinary excretion of $\mathrm{H}^{\mathrm{a}}$-digoxin in a control case (upper), a case of renal failure (left lower) and a case of diabetes mellitus (right lower).

these groups the blood level of the renal failure declined most slowly. At 2 hours after injection the blood levels of 3 groups were already clearly differentiated. As time elapsed the more the difference became the larger. 
The fecal and urinary excretion of radioactivity from the body in each group is shown in Fig. 2. In renal failure urinary excretion was significantly decreased and, on the other hand, fecal excretion was markedly increased. In contrast to this, in diabetes mellitus only slight difference of the way of excretion from control group was obtained. In 10 days, cumulative urinary excretion of radioactivity was 65 per cent in control group, 16 per cent in the group of renal failure and 59 per cent in the group of diabetes mellitus. Cumulative fecal excretion in 10 days was 14 per cent in control, 39 per cent in renal failure and 15 per cent in diabetes mellitus.

The blood levels of 2 and 6 hours after injection were compared individually as is shown in Fig. 3. The difference between each group can be more clearly seen by comparing these levels in individual cases. The value of diabetic group lies between that of renal failure and of control groups. The degree of diabetic state and renal function tests of the diabetic cases studied

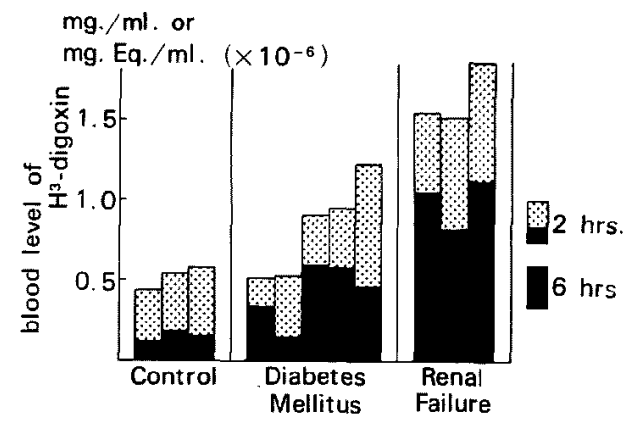

Fig. 3. The blood levels of 2 and 6 hours after injection.

Table III. Diabetic State and Renal Functions of Diabetic Patients

\begin{tabular}{|c|c|c|c|c|c|c|c|c|}
\hline \multirow{2}{*}{$\begin{array}{c}\text { Case } \\
\text { No. }\end{array}$} & \multirow{2}{*}{ Name } & \multirow{2}{*}{$\begin{array}{l}\text { Fasting* } \\
\text { Blood } \\
\text { Sugar }\end{array}$} & \multirow{2}{*}{$\begin{array}{c}\text { Sugar } * * \\
\text { in } \\
\text { Urine }\end{array}$} & \multirow{2}{*}{ Drug Administered } & \multirow{2}{*}{$\begin{array}{c}\text { BUN } \\
\text { (mg./100 } \\
\text { ml. })\end{array}$} & \multicolumn{2}{|c|}{$\operatorname{PSP}(\%)$} & \multirow{2}{*}{$\begin{array}{l}\text { Renal Clearance } \\
\text { (ml./min.) }\end{array}$} \\
\hline & & & & & & $15 \mathrm{~min}$. & 2 hrs. & \\
\hline 4 & Si. S. & 110 & 5 & none & 64 & 10 & 45 & GFR 18.7 \\
\hline 5 & Su. S. & 155 & 40 & none & 18 & 20 & 60 & $\begin{array}{l}\text { GFR } 50.4, \text { RBF } \\
606, \text { RPF } 397\end{array}$ \\
\hline 6 & T. K. & 248 & 5.6 & $\begin{array}{l}\text { Novo lente insulin } \\
12 \text { units }\end{array}$ & 17 & 10 & 55 & $\begin{array}{l}\text { GFR 47, RBF } \\
330, \text { RPF } 192\end{array}$ \\
\hline 7 & S. M. & 282 & 10.6 & $\begin{array}{l}\text { Novo lente insulin } \\
12 \text { units }\end{array}$ & 15 & 20 & 40 & GFR 40 \\
\hline 8 & S. N. & 109 & 0 & $\begin{array}{l}\text { acetohexamide } 1.5 \\
\text { Gm. }\end{array}$ & 14 & 35 & 60 & $\begin{array}{l}\text { GFR } 93.3, \text { RBF } \\
1,291, \text { RPF } 788\end{array}$ \\
\hline
\end{tabular}

* mg. $100 \mathrm{ml}$. mean value for 5 days before this study.

** Gm./day mean value for 5 days before this study. 


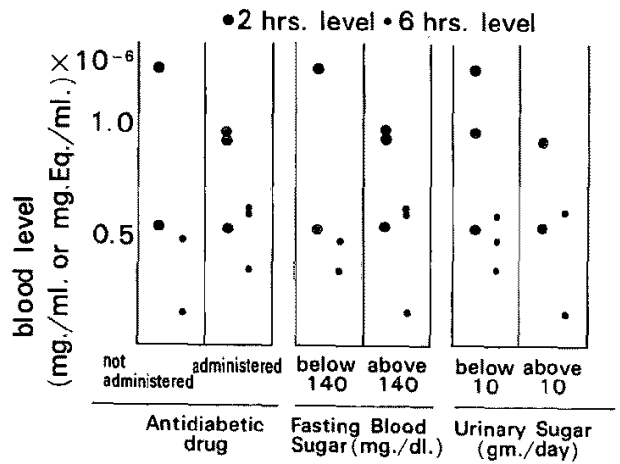

Fig. 4. The relation of diabetic state to blood level of digoxin.

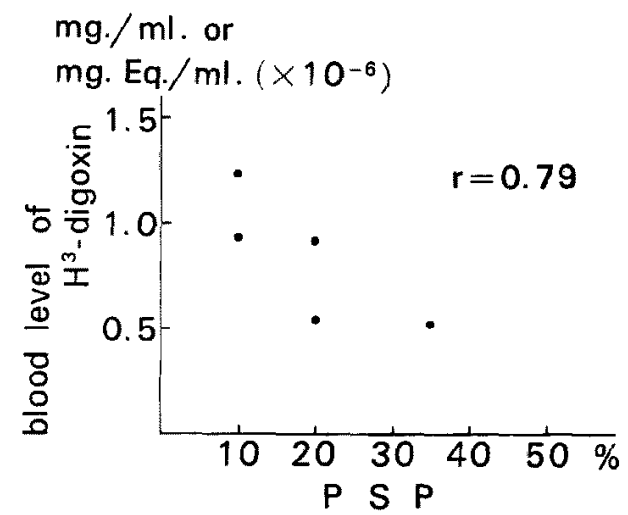

Fig. 5. The relation of PSP to blood level of digoxin.

mg./ml. or

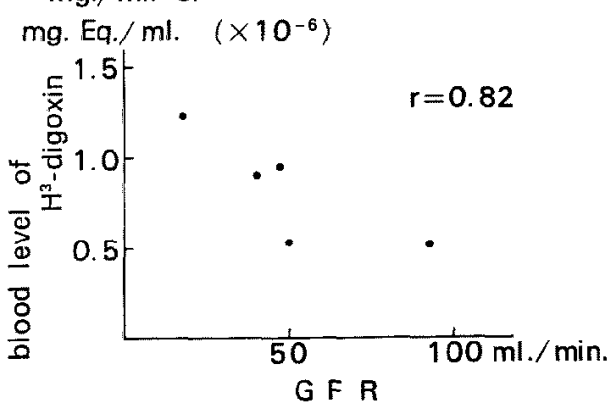

Fig. 6. The relation of GFR to blood level of digoxin.

in this report were listed in Table III. The delayed decline of the levels of digoxin in diabetic cases was observed to have no correlation to the level of fasting blood sugar, the amount of urinary sugar and use of anti-diabetic drugs administered just before this study (Fig. 4). In contrast to this, the blood level, particularly 2 hours after injection, correlated closely to the values of 


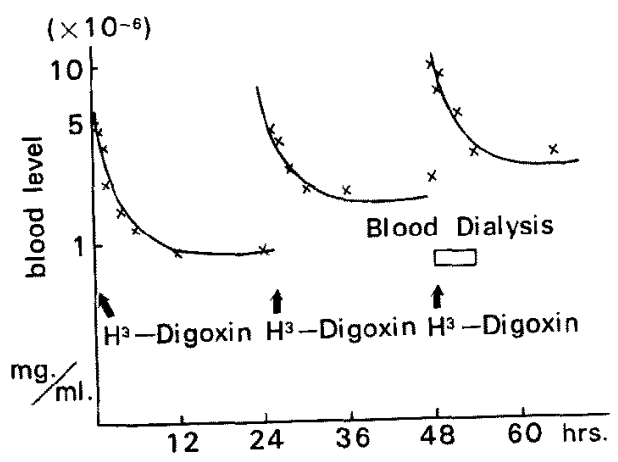

Fig. 7. Effect of blood dialysis on the removal of digoxin in a case of renal failure.

PSP test (Fig. 5) and GFR (Fig. 6). Correlation coefficients of 2 hours blood level were : $r=0.79$ for PSP ( 15 min.), $r=0.74$ for PSP ( 2 hours) and 0.82 for GFR. Those of 6 hours blood level were : $r=0.43$ for PSP (15 min.), $r=0.70$ for PSP ( 2 hours) and $r=0.36$ for GFR.

Effect of blood dialysis in one patient (M.S.) upon the level of blood digoxin was shown in Fig. 7. Equilibrated blood level of radioactivity 24 hours after digoxin injection showed the gradual increase daily and blood dialysis was found to have little effect on the removal of digoxin. Only 3 per cent of radioactivity was found in the dialyzed fluid. In the patient N.A. total amount of peritoneal fluid showed to contain only 6 per cent of the total radioactivity injected.

\section{Discussion}

When digitalis is given to the patients of congestive heart failure associated with renal failure, unexpected side effect of digitalis is seen not infrequently. Several investigators have demonstrated that digitalis was exexcreted mainly by the kindey. ${ }^{3)-5}$, 15) Therefore, in the present study clearance of digoxin in the cases of different degree of renal failure was investigated by using tritium labeled digoxin. The equilibrated blood level of radioactivity of these cases at 24 hours after injection remained high in comparison with control group, showing marked impairment of the urinary excretion of radioactivity. In 10 days the patients of control group excreted in the urine 65 per cent of administered radioactivity, while the patients with renal failure excreted only 16 per cent. Increased fecal excretion of 39 per cent was found in renal failure when compared with 14 per cent excretion in control group.

The amount of metabolites of digoxin released in the human body and in the urine has been much discussed, ${ }^{7)-9), 16)}$ and yet definite conclusion was not 
obtained. According to Marcus et al. ${ }^{6)} 94$ per cent of radioactivity excreted in the first 24 hours' urine was unchanged digoxin. Similarly, Doherty et al.4) showed the excretion of the metabolites of digoxin in the urine to be only 1 or 2 per cent of the total radioactivity. We obtained almost the same results as these data, that is, of the radioactivity collected in the first day more than 90 per cent is unchanged digoxin. Therefore, the blood level of the radioactivity was considered to represent the level of unchanged digoxin although the problem leaves room for further study. The term " miligram equivalent" noted in the chart is employed in view of the above discussion in the same manner as Okita et al. ${ }^{2)}$ These data coincided with the assumption that the kidney was the principal organ for the excretion of digoxin and that in renal failure small dose of digoxin could induce digitalis intoxication easily.

Blood dialysis and periotoneal lavage had little effect on the removal of digoxin with only 3 or 6 per cent excretion of radioactivity administered. Since much potassium ion was removed by these procedures, excess digoxin was considered to induce intoxication more easily.

Even though there were reports on the respective influences of insulin or digitalis on the metabolism of saccharides, the relation of insulin to digitalis has not been clarified. Therefore, in the present study clearance of digoxin in the case of diabetes mellitus was also investigated. The present diabetic state had no direct relation to the clearance of radioactivity, but the degree of impaired renal function was found to be at least one of the major factors of the delayed clearance of digoxin. The blood levels of radioactivities revealed considerably good correlations $(r=0.7$ to 0.8$)$ with the data of PSP test and GFR. Some discrepancy between the data of blood level and those on excretion of labeled digoxin could not be explained at the present time.

\section{SUMMARY}

(1) In renal failure the clearance of digoxin was markedly impaired. The blood level in this group remained high for a long time, urinary excretion was much decreased and fecal excretion was increased. This observation shows that the kidney is the major organ for excretion of digoxin in normal subjects.

(2) Blood dialysis and peritoneal lavage had little effect on removal of digoxin from blood.

(3) In diabetes mellitus where moderate disturbance of digoxin clearance is observed the diabetic state or the usage of anti-diabetic drugs had no influence on clearance of digoxin. The degree of impaired renal function was clearly recognized as a factor of the clearance of digoxin. 


\section{ACKNOWLEDGEMENT}

The authors wish to express their appreciation to Drs. M. Ishii and G. Omori (Dept. of Med., Sensoji Hospital) for the arrangement of some patients. The authors gratefully acknowledge the assistance of Dr. Stanley T. Bloomfield and Mr. James Murphy of Burroughs-Wellcome and Co., Inc., Tuckahoe, New York, in the preparation and free supply of tritiated digoxin.

\section{REFERENCES}

1. Sjoerdsma, A. and Fischer, C. S. : Girculation $4: 100,1951$.

2. Okita, G. T., Kelsey, F. E., Talso, P.J., Smith, L. B., and Ceiling, E. M. K. : Circulation 7: 161, 1953.

3. Spratt, J. L. and Okita, G. T. : J. Pharm. Exper. Therap. 124: 115, 1958.

4. Doherty, J. E., Perkins, W. H., and Mitchell, G. K. : Arch. Int. Med. 108: 531, 1961.

5. Doherty, J. E., Perkins, W. H., and Wilson, M. C. : Am. J. Med. 37: 536, 1964.

6. Marcus, F. I., Kapadia, G. J., and Kapadia, G. G. : J. Pharm. Exper. Therap. 145: 203, 1964.

7. Marcus, F. I., Sales, A. F., Peterson, A. S., Scully, J., and Kapadia, G. G. : J. Pharm. Exper. Therap. $152 ; 372,1966$.

8. Harrison, G. E., Brandenburg, R. O., Ongley, P. A., Orvis, A. L., and Owen, C. A. : J. Lab. Clin. Med. 67: 764, 1966.

9. Lage, G. L. and Spratt, J. L. : J. Pharm. Exper. Therap. $149: 248,1965$.

10. Gonzalez, L. F. and Layne, E. C. : J. Clin. Invest. 39: 1578, 1960.

11. Wilzbach, K. E. : J. Amer. Chem. Soc. 79: 1013, 1957.

12. Hautmann, A. C. : Int. J. Appl. Rad. Isotopes 16: 65, 1965.

13. Kelly, R. G., Peets, L. E. A., Gordon, S., and Buyske, D. A. : Anal. Biochem. 2 : 267, 1961.

14. Gisvold, O, and Wright, S. E. : J. Amer. Pharmaceut. Ass. 46 : 535, 1957.

15. Friedman, M., St. George, S., and Bine, R. : Medicine $33: 15,1954$.

16. Brown, B. T. and Wright, S. E. : J. Biol. Chem. 220:431, 1956. 